\title{
Chemicals Mitigate Copper Toxicity on Seed Germination and Plant Growth
}

ISSN: 2637-7659

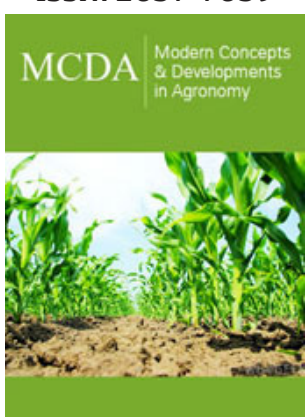

*Corresponding author: Marouane Ben Massoud, University of Carthage, Faculty of Sciences of Bizerte, LR18ES38 Plant Toxicology and Environmental Microbiology, 7021 Zarzouna, Tunisia School of Biological, Earth and Environmental Sciences, University College Cork, Distillery Fields, North Mall Cork, Ireland

Submission: 監 May 24, 2021

Published: 䒸June 02, 2021

Volume 8 - Issue 4

How to cite this article: Marouane Ben Massoud*, Oussama Kharbech, Abdelilah Chaoui. Chemicals Mitigate Copper Toxicity on Seed Germination and Plant Growth. Mod Concep Dev Agrono. 8(4). MCDA. 000695. 2021. DOI: 10.31031/MCDA.2021.08.000695

Copyright@ Marouane Ben Massoud. This article is distributed under the terms of the Creative Commons Attribution 4.0 International License, which permits unrestricted use and redistribution provided that the original author and source are credited.

\author{
Marouane Ben Massoud ${ }^{1,2 *}$, Oussama Kharbech ${ }^{1}$ and Abdelilah Chaoui ${ }^{1}$ \\ ${ }^{1}$ University of Carthage, Faculty of Sciences of Bizerte, LR18ES38 Plant Toxicology and \\ Environmental Microbiology, 7021 Zarzouna, Tunisia
}

${ }^{2}$ School of Biological, Earth and Environmental Sciences, University College Cork, Distillery Fields, North Mall Cork, Ireland

\begin{abstract}
The present mini review aimed to explain the potential protective role of some chemicals against Copper $\mathrm{Cu}$ ) toxicity in plant. Many studies suggest that the exogenous supply of effectors such as nitric oxide, polyamines, organic acids and growth regulators to germinating seeds can be a promising alternative to improve plant response to heavy metal stress.
\end{abstract}

\section{Introduction}

Heavy metal stress is one of the environmental pollution situations affecting plant growth and productivity. Copper is an essential oligo-element, but can be toxic to most plants, even at very low concentration [1,2]. Due to its wide use in fungicides, pesticides and fertilizers, pollution by $\mathrm{Cu}$ has become increasingly a major environmental problem: inhibition of plant growth [3], resulting from numerous physiological and metabolic disturbances, is generally reported as a consequence of an excess of $\mathrm{Cu}$ [1]. Copper is readily absorbed by plants, leading to toxic symptoms of physiological and biochemical dysfunctions, such as disorders in mineral nutrition [4] and photosynthesis [5], deterioration of membrane integrity and, in general, induction of oxidative stress due to overproduction of reactive oxygen species (ROS) [1,2].

ROS are considered to be both (i) harmful to cells [6] and (ii) ubiquitous signaling molecules participating in the stress response of plants [7]. Like other environmental stresses, $\mathrm{Cu}$ excess results in changes in

a) antioxidant enzyme activities, such as superoxide dismutase, catalase and peroxidases, and

b) contents of low-molecular-weight non-enzymatic antioxidants, such as ascorbic acid and glutathione.

Most of the abiotic stress impact studies in plants have been carried out for individually applied pollutants, although contamination, which really involves soils and plants, is multiple rather than simple. Soils are often contaminated with several pollutants at the same time. In such situations, contaminants can interact with one another in a synergistic, additive or protective manner [8].

Several researchers suggested that it would be important to develop practical techniques to mitigate the effects of heavy metal stress, such as the simultaneous application of nitric oxide [9], polyamines [10], sulfur [11], calcium [12], citrate [1], hydrogen peroxide [13], growth regulators [14], and hydrogen sulfide $[15,16]$, which neutralize the toxic effect of heavy metals on germination and plant growth and thereby improve plant resistance. 
Many chemicals have the capacity to trap and sequester metal cations inside cells. The strong affinity to the binding of heavy metals is due to the electronegativity of functions in these molecules; in particular carboxyl groups (-COO-). This is the case with EDTA [17] and organic acids (malic, oxalic, citric, benzoic) [1,18,19].

However, the action of the chelators remains controversial. These compounds can improve the solubility of metal cations in the rhizosphere and, as a result, their uptake by roots. In this case, they are useful in ongoing phytoextraction programs that are relevant to the phytoremediation stream $[17,20]$.

Chelators also participate in intracellular detoxification: vacuolar shuttles in the form of "metal-organic acid" complexes eliminate the heavy metals from the cytoplasm [18,21]. A third possibility would be an indirect action of certain carboxylic acids (citrate) in improving the antioxidant capacities of plants previously contaminated with heavy metals $[18,22,23]$.

\section{Conclusion}

Clarification of why $\mathrm{Cu}$ phytotoxicity could be mitigated by exogenous effectors application should provide a basis for early monitoring and assessment of contamination of the plant environment. At least in part, the protection of plants against the toxicity of heavy metals is associated with the control of their removal.

\section{Acknowledgment}

This work was supported by the Tunisian Ministry of Higher Education and Scientific Research (LR18ES38).

\section{References}

1. Maksymiec W (2007) Signaling responses in plants to heavy metal stress. Acta physiologia Plantarum 29: 117-187.

2. Ben Massoud M, Sakouhi L, Karmous I, Zhu Y, El Ferjani E, et al. (2018) Protective role of exogenous phytohormones on redox status in pea seedlings under copper stress. Journal of Plant Physiology 221: 51-61.

3. Ben Massoud M, Karmous I, El Ferjani E, Chaoui A (2017) Alleviation of copper toxicity in germinating pea seeds by IAA, $\mathrm{GA}_{3}$, Ca and citric acid. Journal of Plant Interactions 13(1): 21-29.

4. Fernandes JC, Henriques FS (1991) Biochemical, physiological and structural effects of excess copper in plants. The Botanical Review 57: 246-273.

5. Connan S, Stengel DB (2011) Impacts of ambient salinity and copper on brown alga: 1. Interactive effects on photosynthesis, growth, and copper accumulation. Aquat Toxicol 104(1-2): 94-107.

6. Apel K, Hirt H (2004) Reactive oxygen species: metabolism, oxidative stress, and signal transduction. Annual Review of Plant Biology 55: 373399.

7. Foyer CH, Noctor G (2005) Oxidant and antioxidant signaling in plants: re-evaluation of the concept of oxidative stress in a physiological context. Plant and Cell Environment 28(8): 1056-1071.

8. Chaoui A, El Ferjani E (2013) $\beta$-Estradiol protects embryo growth from heavy-metal toxicity in germinating lentil seeds. Journal of Plant Growth Regulation 32: 636-645.
9. Kharbech O, Houmani H, Chaoui A, Corpas FJ (2017) Alleviation of $\mathrm{Cr}$ (VI)-induced oxidative stress in maize (Zea mays L.) seedlings by NO and $\mathrm{H}_{2} \mathrm{~S}$ donors through differential organ-dependent regulation of ROS and NADPH-recycling metabolisms. J Plant Physiol 219: 71-80.

10. Choudhary SP, Oral HV, Bhardwaj R, Yu JQ, Tran LSP (2012) Interaction of brassinosteroids and polyamines enhances copper stress tolerance in Raphanus Sativus. J Exp Bot 63(15): 5659-5675.

11. Anjum NA, Umar S, Ahmad A, Iqbal M, Khan NA (2008) Sulphur protects mustard (Brassica campestris L.) from cadmium toxicity by improving leaf ascorbate and glutathione. Plant Growth Regulation 54: 271-279.

12. Wang CQ, Song H (2009) Calcium protects Trifolium repens L. seedlings against cadmium stress. Plant Cell Rep 28(9): 1341-1349.

13. Hu Y, Ge Y, Zhang C, Ju T, Cheng W (2009) Cadmium toxicity and translocation in rice seedlings are reduced by hydrogen peroxide pretreatment. Plant Growth Regulation 59: 51-61.

14. Meng HB, Hua SJ, Shamsi IH, Jilani J, Li YL, et al. (2009) Cadmiuminduced stress on the seed germination and seedling growth of Brassica napus L. and its alleviation through exogenous plant growth regulators. Plant Growth Regulation 58:47-59.

15. Kharbech O, Sakouhi L, Ben Massoud M, Mur LAJ, Corpas FJ, et al. (2020) Nitric oxide and hydrogen sulfide protect plasma membrane integrity and mitigate chromium-induced methylglyoxal toxicity in maize seedlings. Plant Physiol Biochem157: 244-255.

16. Kharbech O, Ben Massoud M, Sakouhi L, Djebali W, Mur LAJ, et al. (2020) Exogenous application of hydrogen sulfide reduces chromium toxicity in maize seedlings by suppressing NADPH oxidase activities and methylglyoxal accumulation. Plant Physiology and Biochemistry 154: 646-656.

17. Sakouhi L, Kharbech O, Ben Massoud M, Gharsallah C, Ben Hassine S, et al. (2020) Calcium and ethylene glycol tetraacetic acid mitigate toxicity and alteration of gene expression associated with cadmium stress in chickpea (Cicer arietinum L.) shoots. Protoplasma.

18. Gao Y, Miao C, Xia J, Luo C, Mao L, et al. (2012) Effect of citric acid on phytoextraction and antioxidative defense in Solanum nigrum L. as a hyperaccumulator under $\mathrm{Cd}$ and $\mathrm{Pb}$ combined pollution. Environmental Earth Sciences 65: 1923-1932.

19. Sakouhi L, Kharbech O, Ben Massoud M, Munemasa S, Murata Y, et al. (2021) Oxalic acid mitigates cadmium toxicity in Cicer arietinum L. germinating seeds by maintaining the cellular redox homeostasis. Journal of Plant Growth Regulation.

20. Liu EE, Luo W, Zhou H, Peng XX (2009) Determination of oxalate in plant tissues with oxalate oxidase prepared from wheat. Biologiae Plantarum 53(1): 129-132.

21. Prietoa C, Lozanoa JC, Rodríguezb PB, Toméb FV (2013) Enhancing radium solubilization in soils by citrate, EDTA, and EDDS chelating. Amendments J of Hazardous Materials 250-251: 439-446.

22. Mihalíka J, Hennerb P, Frelonb S, Camillerib V, Févrierb L (2012) Citrate assisted phytoextraction of uranium by sunflowers: Study of fluxes in soils and plants and resulting intra-planta distribution of Fe and U. Environmental and Experimental Botany 77: 249-258.

23. Miszalskia Z, Kornasa A, Rozpadekc P, Fischer-Schliebsb E, Lüttge U (2013) Independent fluctuations of malate and citrate in the CAM species Clusia hilariana Schltdl. under low light and high light in relation to photoprotection. J Plant Physiol 170: 453-458.

For possible submissions Click below: 